\title{
Performance of X-ray Microanalysis in the Variable Pressure or Environmental Scanning Electron Microscope
}

\author{
J-F Le Berre*, K. Robertson*, R. Gauvin* and G.P. Demopoulos* \\ * Department of Mining, Metals and Materials Engineering, McGill University, 3610 \\ University Street, Montreal, Québec, Canada, H3A 2B2
}

The variable pressure or environmental scanning electron microscope (VP-SEM ; ESEM) is a technique which allows the imaging and the analysis of materials without coating. The performance of X-ray microanalysis with this technique has two main limitations : charging and skirting.

Charging occurs when a material cannot effectively conduct the beam energy imparted to it. Its effect is a modification of X-ray emission. Charging can be minimized by using the appropriate experimental conditions.

Skirting is the result of elastic and inelastic scattering of primary electrons with gas molecules. The consequence is that scattered electrons in the skirt interact outside of the focalized beam and generate X-rays which are not representative. Two types of correction methods have been developed to take into account the skirting : the beam-stop method and the pressure variation method.

Two pressure variation method are the Doehne and the Gauvin ones. The Doehne method is based on the variation of X-ray intensity with pressure [1]. An empirical factor D is used to correct changes in the background shape. Two assumptions are made : Spectrum A pressure is twice spectrum B pressure and changes in skirt intensity are more important than the skirt radius as validated by Danilatos (1988).

The Gauvin method is based on the fraction of the non-scattered electrons fp [2]. The main advantage of Gauvin's method is its validity in the total range of pressure and the absence of assumptions on the variation of the x-ray intensity with pressure. This variation is not always linear at high pressure.

The experiments were performed on a $\mathrm{Cu}_{2} \mathrm{~S}$ sample mounted on a conductive bakelite. The sample was composed of particle less than $20 \mu \mathrm{m}$. The microscope used was the Hitachi S-3000N, the gas used was air, and the experiments were performed at $30 \mathrm{keV}$.

The Doehne and the Gauvin methods seem to give the same type of results (Table 1). Those obtained are close to the value at $0 \mathrm{~Pa}$ (deviation less than 10\%). Nevertheless, the Doehne method appears to be D dependent (Table 2), and the accuracy of the results will depend of the precision on the $\mathrm{D}$ value. In opposition, the Gauvin method is independent of the choice of pressures and it is not only useful to obtain the X-ray intensities, but also a very accurate spectrum can be obtained using this method (Figure 2).

\section{References}

[1] E.Doehne, Scanning 19 (1997) 75-78.

[2] R.Gauvin, Scanning, 21 (1999) 388-393. 

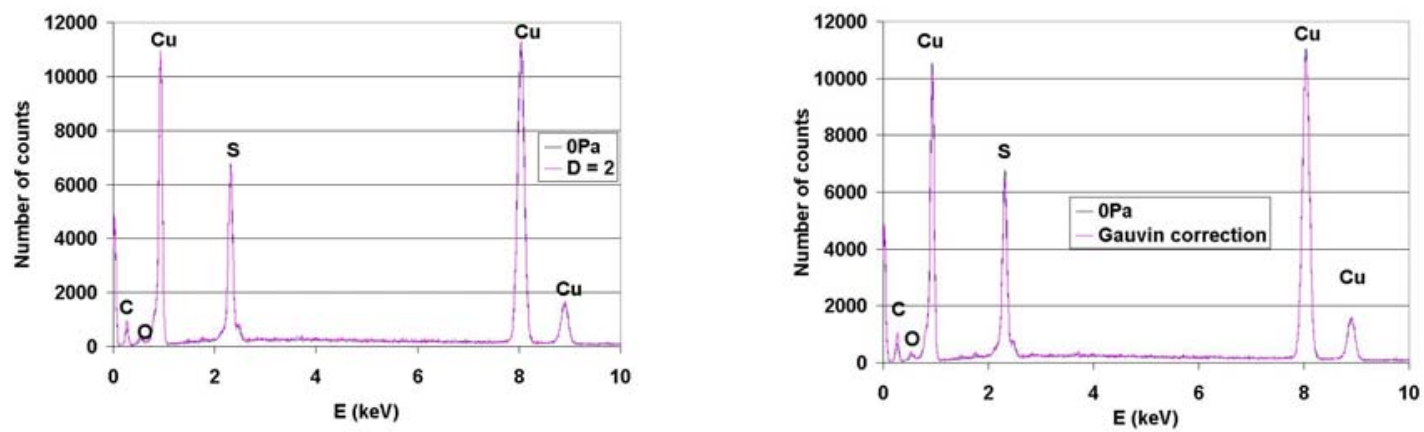

Figure 1. (a) Spectrum obtained using the Doehne method $(\mathrm{D}=2)$ for $\mathrm{P}_{1}=100 \mathrm{~Pa}$ and $\mathrm{P}_{2}$ $=200 \mathrm{~Pa}$; (b) Spectrum obtained by the Gauvin method for $\mathrm{P}_{1}=100 \mathrm{~Pa}$ and $\mathrm{P}_{2}=200 \mathrm{~Pa}$.

Table 1. Comparison between the Doehne and the Gauvin methods for $\mathrm{P}_{1}=2 \mathrm{P}_{2}$

\begin{tabular}{|c|c|c|}
\hline I K Cu / I K S & Doehne & Gauvin \\
\hline $100 \mathrm{~Pa}-200 \mathrm{~Pa}$ & 2.63 & 2.61 \\
\hline $50 \mathrm{~Pa}-100 \mathrm{~Pa}$ & 2.49 & 2.49 \\
\hline $5 \mathrm{~Pa}-10 \mathrm{~Pa}$ & 2.44 & 2.43 \\
\hline
\end{tabular}

Table 2. D dependence of the Doehne method for $\mathrm{P}_{1}=200 \mathrm{~Pa}$

$$
\text { and } \mathrm{P}_{2}=100 \mathrm{~Pa}
$$

\begin{tabular}{|c|c|}
\hline $\mathbf{D}$ & $\mathbf{I K ~ C u}$ / I K S \\
\hline 1 & 2.58 \\
\hline 1.5 & 2.60 \\
\hline 2 & 2.62 \\
\hline 2.4 & 2.63 \\
\hline 2.5 & 2.63 \\
\hline 3 & 2.64 \\
\hline
\end{tabular}

For $\mathrm{P}=0 \mathrm{~Pa}: \mathrm{I} \mathrm{K} \mathrm{Cu} / \mathrm{I} \mathrm{K} \mathrm{S}=2.46$
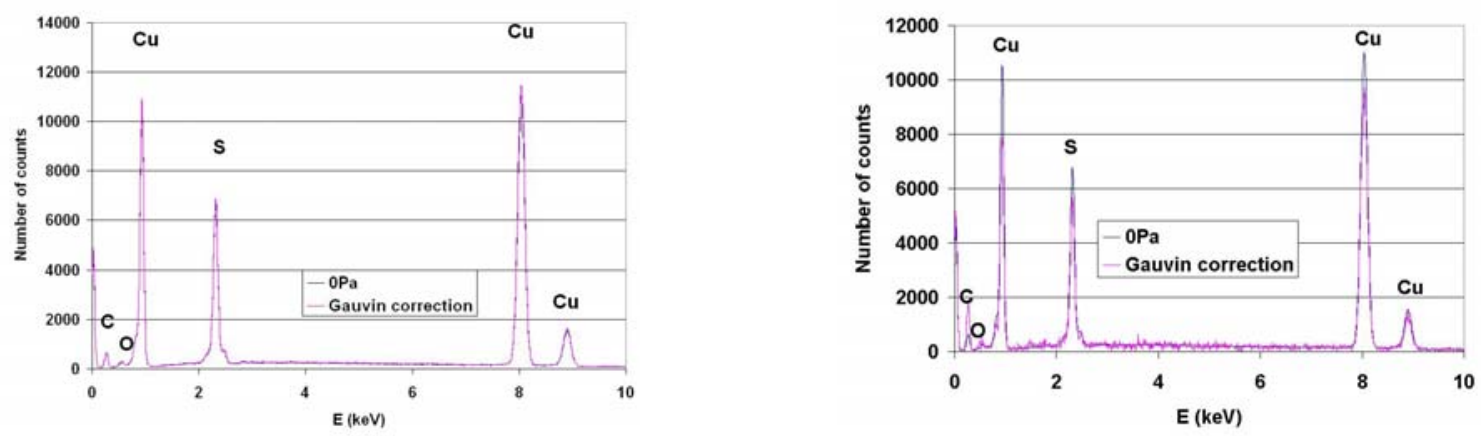

Figure 2. (a) Spectrum obtained by the Gauvin method by choosing $\mathrm{P}_{1}=10 \mathrm{~Pa}$ and $\mathrm{P}_{2}=$ $200 \mathrm{~Pa}(\mathrm{I} \mathrm{K} \mathrm{Cu} / \mathrm{I} \mathrm{K} \mathrm{S} \mathrm{=} \mathrm{2.51)} \mathrm{;} \mathrm{(b)} \mathrm{Spectrum} \mathrm{obtained} \mathrm{by} \mathrm{the} \mathrm{Gauvin} \mathrm{method} \mathrm{by}$ choosing $\mathrm{P}_{1}=150 \mathrm{~Pa}$ and $\mathrm{P}_{2}=200 \mathrm{~Pa}(\mathrm{I} \mathrm{K} \mathrm{Cu} / \mathrm{I} \mathrm{K} \mathrm{S}=2.59)$ 